\title{
Volver a la "comunidad" con Karl Marx. Una revisión crítica de la dicotomía comunidad-sociedad $^{1}$
}

\section{Return to the "community" with Karl Marx. A critical review of community-society dichotomy}

\author{
Mónica Iglesias Vázquez² \\ Universidad Nacional Autónoma de México (México)
}

Recibido: 27-01-15

Aprobado: 06-04-15

\section{Resumen}

En las últimas décadas el concepto de "comunidad" ha experimentado un aggiornamento inusitado, que se ha tratado de explicar por la incapacidad de la moderna sociedad capitalista para generar bienestar económico y social y, sobre todo, por sus efectos lacerantes sobre la identidad, la afectividad y los vínculos entre los seres humanos y de éstos con la naturaleza. Desde un enfoque sociológico, el renacimiento de "lo comunitario" actualiza uno de los debates fundantes de la sociología: aquel que contrapone sociedad y comunidad. Aquí proponemos recuperar algunos de los postulados marxianos a propósito de la comunidad, para examinar a partir de este autor la potencialidad que alberga el concepto para pensar la humanización. Nuestra hipótesis es que Marx emplea

\footnotetext{
${ }^{1}$ Una versión preliminar de este trabajo fue presentada como ponencia en el Coloquio "Karl Marx a 195 años de su nacimiento. El regreso del topo", celebrado entre los días 6 y 9 de mayo de 2013, en la Universidad Nacional Autónoma de México.

2 (monicaiglesias@hotmail.com). Licenciada en Sociología (Universidad de Barcelona); Maestra y Doctora en Estudios Latinoamericanos (Universidad Nacional Autónoma de México). Entre sus publicaciones más recientes están los artículos "Lo social y lo político en Chile: Itinerario de un desencuentro teórico y práctico" (Izquierdas, n 22, Santiago de Chile, enero 2015); "El movimiento de los pobladores" (Crónica Popular, Suplemento CELAC, n 4, Madrid, septiembre 2013); "Teoría en movimiento: más de una década de pensamiento crítico" (OSAL, n 30, CLACSO, Buenos Aires, octubre 2011); "Chile-Cronología del conflicto social 2010" (OSAL, n 29, CLACSO, Buenos Aires, mayo 2011); y el libro Rompiendo el cerco. El movimiento de pobladores contra la dictadura (Santiago de Chile, RUCh, 2011).
} 
dos sentidos de comunidad, uno de los cuales implica la reapropiación consciente de los vínculos sociales por parte de las personas y la capacidad de establecer relaciones más humanas.

Palabras-clave: comunidad, sociedad, Karl Marx, movimientos comunitarios, movimientos sociales.

\begin{abstract}
In recent decades the concept of "community" has experienced an unprecedented aggiornamento, which has been tried to explain by the inability of modern capitalist society to generate economic and social wellbeing and, above all, for their devastating effects on identity, affectivity and the links between human beings and of these with nature. From a sociological approach, the revival of 'community' updates one of the founding debates of sociology: that which opposes society and community. Here we propose to recover some of the marxian postulates about the community to examine from this author the potential of this concept to think the humanization. Our hypothesis is that Marx uses two senses of community, one of which involves conscious re-appropriation of social ties by the people and the ability to establish more human relationships.
\end{abstract}

Key-words: community, society, Karl Marx, community movements, social movements.

Es tan ridiculo sentir nostalgia de aquella plenitud primitiva como creer que es preciso detenerse en este vaciamiento completo.

(Marx 2011[1857-1858]: 90)

\title{
Introducción
}

"Comunidad" y "sociedad" constituyen dos conceptos que, al menos desde los albores del siglo XX, con la consolidación de la sociología como disciplina científica, se asentaron -tanto en el ámbito especializado de la academia como en el imaginario colectivo- como dos entidades absolutamente distintas y, más aún, antagónicas. El sociólogo alemán Ferdinand Tönnies los fijó, en su obra Comunidad y sociedad (1887)3 , como una suerte de "tipos ideales", según la terminología ulterior de su colega y compatriota, Max

3 Significativamente subtitulada, en su primera edición, "Tratado sobre el comunismo y el socialismo como formas empíricas de cultura”; véase Farfán (1998: 209). 
Weber. Éste y el francés Émile Durkheim también reflexionaron sobre esta dicotomía, aunque con inclinaciones distintas: mientras que Weber recuperó ampliamente a Tönnies expresando cierto pesar ante la destrucción de las formas comunitarias, Durkheim se mostró mucho más optimista respecto del progreso que suponía, a su parecer, la transición desde la "solidaridad mecánica" a la "solidaridad orgánica". El despegue de la sociología, esto es, de la preocupación por comprender cientificamente las "leyes" que rigen las relaciones sociales coincide -no casualmente-con el despliegue del capitalismo y el desarrollo de sus contradicciones, en el siglo XIX. El estudio de la sociedad está intrínsecamente ligado, entonces, al estudio del capitalismo y, por ende, de la sociedad burguesa. La transición del feudalismo al capitalismo, en Europa, implicó la modificación de las estructuras económicas previas y la disolución de las relaciones sociales a ellas asociadas. Así pues, la sociedad capitalista apareció como un torbellino que iba desmantelando las formas de cohesión social vigentes. La sociedad naciente -global, urbana, fundada en relaciones impersonales e independientes- se erigía sobre los restos de las comunidades particulares -locales, rurales, donde las relaciones (cara a cara) estaban condicionadas, fundamentalmente, por lazos basados en la sangre, la tradición y la religión-.

Desde los estudios de los "padres fundadores" de la sociología, y tras un intervalo en que la discusión pareció estar zanjada con el triunfo del paradigma modernizador -que suponía o bien la extinción de las formas comunitarias ante la superioridad de la sociedad moderna o bien su sometimiento como formas necesarias para el "bienestar" social pero subordinadas y con funciones claramente circunscritas al aspecto emotivo e integrador-, la problemática de la articulación entre comunidad y sociedad volvió a emerger como una preocupación relevante del pensamiento social desde la década de los ochenta. Desde una perspectiva filosófica diversos autores indagaron las posibilidades del concepto de comunidad para repensar la convivencia humana (Nancy, 2000[1983]; Agamben, 1996[1990]; Esposito, 2003[1998]). Desde una óptica más propiamente sociológica y latinoamericana encontramos los trabajos, más recientes, de los sociólogos bolivianos Raúl Prada (2008) y Álvaro García (2009), anclados en su conocimiento vivencial de las comunidades

\footnotetext{
${ }^{4}$ En la obra de Weber la comunidad aparece bajo distintas perspectivas: como parte del relato histórico, como un tipo ideal sociológico y como un artefacto político-utópico; véase De Marinis (2010b). Durkheim expuso estos conceptos en su tesis doctoral sobre La división del trabajo social (2001[1893]) para dar cuenta, precisamente, de la transición desde sociedades cohesionadas por la semejanza de sus miembros (con escasa o nula división del trabajo y, por lo tanto, diferenciación interna) a aquellas fundadas sobre la división del trabajo y la complementariedad de funciones y relaciones específicas que ella comporta. Para una revisión y comparación sintética de los postulados de los sociólogos clásicos al respecto de esta polaridad conceptual ver De Marinis (2010a) y, en general, el número monográfico sobre la construcción de la comunidad que organizó ese autor, en el que está publicado el artículo. Una lectura de Tönnies en el sentido aludido en Farfán (1998).
} 
indígenas andinas, en los que ambos autores recuperan aspectos fundamentales de la "forma comunidad" - en términos de García- para pensar la transición, ahora del capitalismo a otro modo de existencia centrado en la valorización de la vida y de la naturaleza -condensado en la expresión sumak kawsay o suma qamaña- ${ }^{5}$. Estos trabajos exploran la vinculación existente entre las características de la comunidad (indígena) y las más recientes movilizaciones que han protagonizado los pueblos andinos. Prada sostiene que "la subversión indígena tiene como institución subyacente el ayllu, la comunidad, que hace de estructurante de las movilizaciones" (2008). La centralidad de las comunidades indígenas en las luchas anticapitalistas actuales mostró una de las formas posibles del comunismo, entendido como el "movimiento real que anula y supera (aufhebt) al estado de cosas actual" (Marx y Engels, 1958[1846]: 37). En ambos trabajos destaca la recuperación del pensamiento marxista para analizar la comunidad, a partir del examen de sus luchas concretas; una veta que no había sido suficientemente explorada hasta entonces.

El propósito primordial de Karl Marx, en cuanto científico social, fue desentrañar las "leyes" que regían el funcionamiento de la sociedad de su época, esto es, la sociedad burguesa. Quizás por ello, la coexistencia temporal de formaciones económico-sociales diferentes -aunque subordinadas unas a otras-, o la transición entre ellas, no constituyen tópicos centrales de su crítica de la economía política ${ }^{6}$. Por consiguiente, la presencia de comunidades tendió a ser leída como un vestigio del pasado, compelido a desaparecer ante el avance imparable del ethos capitalista. Aun así, es posible encontrar en los trabajos del filósofo alemán sugerentes apuntes a propósito de la caracterización de algunas de aquellas sociedades distintas de la burguesa, de los mecanismos que habían operado la transición desde los modos de producción pre-capitalistas al capitalismo, y sobre las condiciones de posibilidad de la eclosión de una sociedad comunista y los rasgos principales que ésta habría de exhibir. Estas reflexiones atraviesan el grueso de su obra de forma intermitente y adquirieron, en algunos momentos, considerable densidad, como en el intercambio epistolar sostenido con los populistas rusos y, especialmente, con la revolucionaria marxista Vera Zasúlich, acerca de las potencialidades de la comunidad rural rusa -la obschina- para impulsar la transición hacia el socialismo sin necesidad de atravesar por las distintas "fases" del desarrollo capitalista y sin disolverse en ese proceso.

\footnotetext{
${ }^{5}$ Expresiones kichwa y aymara, respectivamente, que se remiten a la idea de buen vivir o vivir bien, de acuerdo con la cosmovisión de esos pueblos originarios.

${ }^{6}$ Aunque de manera tangencial se refirió a estas cuestiones, por ejemplo en el capítulo XXIV de El Capital, sobre "La llamada acumulación originaria" (Marx, 2013[1867]: 891-967), dedicado a la transición desde el feudalismo al capitalismo. O en los Elementos fundamentales para la crítica de la economía politica (Grundrisse) 1857-1858, sobre las "Formas que preceden a la producción capitalista (acerca del proceso que precede a la formación de la relación de capital o a la acumulación originaria)" (Marx, 2011[1857-1858]: 433-477).
} 
La finalidad de este artículo es revisitar a Marx para recuperar sus planteamientos a propósito de la "comunidad" y pensar desde allí las posibilidades de este concepto para comprender los procesos de lucha y democratización de la sociedad que tienen lugar en el presente. Para ello, proponemos, en primer lugar, situar de manera "prospectiva" -toda vez que el debate alcanzó relevancia sociológica años después del fallecimiento del filósofo alemánlos planteamientos de Marx en la dicotomía que contrapone la sociedad a la comunidad para, a continuación, dar cuenta de la sociedad capitalista como una forma de no-sociedad, en la que el vínculo social aparece invertido o enajenado; y finalmente recuperar los sentidos en los que Marx se refiere a la comunidad. Por último, esbozaremos algunas consideraciones acerca de las posibilidades que nos provee el pensamiento de Marx - no en vano el principal crítico de la sociedad capitalista- para pensar y resignificar actualmente la comunidad y los debates en torno al carácter comunitario de los movimientos sociales o a la naturaleza de las comunidades movilizadas.

\section{¿Comunidad versus sociedad?}

Comencemos señalando que, de algún modo, Marx no se encuentra en radical oposición al consenso imperante durante el siglo XIX y principios del XX, según el cual la sociedad (capitalista) se imponía arrasando con las comunidades existentes, por lo que "comunidad" y "sociedad" también adquieren en el filósofo de Tréveris connotaciones que, en cierto nivel, las confrontan como dos formas de sociabilidad esencialmente diferentes y opuestas ${ }^{7}$. Sin embargo, esta contradicción sólo es tal en la medida en que la sociedad capitalista se funda sobre una forma de relación interhumana (de interdependencia) no social, como veremos en el siguiente apartado. Abordemos, en primer lugar, el examen de la relación existente entre "lo común" y "lo social" en la perspectiva marxiana.

\footnotetext{
7 Es necesario anotar aquí la dificultad que entraña este acercamiento a la obra de Marx desde el punto de vista de la traducción. Si bien la palabra alemana "Gesellschaft" no debiera comportar problemas, ya que se traduce habitualmente como "sociedad", hemos identificado pasajes en los que es substituida por "comunidad"; véase al respecto Marx (1968[1844]: 117). Mucho más compleja resulta la palabra "comunidad" que puede escribirse en lengua germánica de dos formas diferentes - "Gemeinschaft" y "Gemeinwesen"- y que no tienen el mismo significado, aunque lamentablemente en las traducciones de la obra de Marx han sido vertidas indistintamente como "comunidad". A las dificultades típicas de la traducción terminológica, se añade en este caso una problemática conceptual, por cuanto lo que tratamos de indagar es precisamente el sentido que atribuía Marx a la comunidad, y observamos en su pensamiento dos maneras de concebirla: la primera - "Gemeinschaft"- alude a las comunidades pretéritas, en el sentido que habitualmente toma el término en castellano, como formas distintas de sociabilidad versus la sociedad moderna, comunidades vinculadas por lazos de sangre, de vecindad o de espíritu; en cambio el uso de "Gemeinwesen" está reservado a la verdadera comunidad social, a la comunidad en un sentido positivo, y por lo tanto a la comunidad futura. Engels, por ejemplo, lo empleará para referirse a la commune (como en el caso de la Comuna de París). Esta es, precisamente, la hipótesis que contrastamos en este artículo.
} 
No cabe duda de que, para Marx, el modo de producción es la espina dorsal de las diversas formaciones sociales. De hecho es en, y con, el trabajo como los hombres y las mujeres se producen a sí mismos. Por eso en los Cuadernos de París afirma: "El intercambio, tanto de la actividad humana en el propio proceso de producción como de los productos humanos entre sí, equivale a la actividad genérica y al goce genérico, cuyo modo de existencia real, consciente y verdadero es la actividad social y el goce social" (Marx, 1974[1844]: 136$137)^{8}$.

Esta idea la confirmará posteriormente en su obra magna, El Capital, en el apartado referido específicamente al proceso de trabajo: "Al operar [el trabajador] por medio de ese movimiento sobre la naturaleza exterior a él y transformarla, transforma a la vez su propia naturaleza" (Marx, 2011[1867]: 215-216). Esa naturaleza o esencia humana no es otra cosa que "el conjunto de las relaciones sociales", como sostiene en la sexta de las "Tesis sobre Feuerbach" (Marx, 1845); luego la esencia humana no es "algo abstracto inherente a cada individuo" y, por lo tanto, tampoco algo fijo, inalterable y a-histórico, sino el modo real y concreto que adquieren las relaciones sociales en cada etapa histórica9. En otro lugar el filósofo sostiene: "Por cuanto el verdadero ser comunitario es la esencia humana, los hombres, al poner en acción su esencia, crean, producen la comunidad humana, la entidad social, que no es un poder abstracto-universal, enfrentado al individuo singular, sino la esencia de cada individuo, su propia actividad, su propia vida, su propio goce, su propia riqueza" (Marx, 1974[1844]: 137).

Por consiguiente, la propia realización de la existencia humana produce inmediatamente una determinada forma de ser de la comunidad. El hecho de que los hombres y las mujeres, a través de sus relaciones mutuas y con la naturaleza, produzcan su comunidad y se produzcan a sí mismos es un hecho absolutamente incontrovertible. Lo hacen aunque no lo sepan, lo hacen bajo todas las formas existentes de sociedad. Por ejemplo, bajo el modo de producción capitalista, "el trabajo no produce solamente mercancías; se produce también a sí mismo y produce al obrero como una mercancía" (Marx, 1968[1844]: 75). Sabemos, también, que no lo hacen a su "libre arbitrio" (Marx, 1971[1852]: 226), pero hombres y mujeres tienen la capacidad de dar forma, dentro de ciertos límites, a su organización social. De este modo, la sociedad produce al hombre y a la mujer en cuanto que tales, en cuanto seres sociales y, a su vez, aquélla es producida por ellos. Pero la consciencia de ese hecho (es decir, del poder de los

\footnotetext{
${ }^{8}$ Las cursivas en todas las citas son mías.

${ }^{9}$ La comunidad humana es producida por los seres humanos y éstos, por medio de la comunidad, se producen a sí mismos, no sólo en el sentido que señalara Engels en El origen de la familia, la propiedad privada y el Estado, como "producción del hombre mismo" (Engels, s/f [1884]: 4), es decir, como procreación o continuación de la especie, sino también como producción de la esencia humana, de lo que en cada momento histórico entendemos por "ser humano".
} 
seres humanos para modelar su existencia), es precisamente lo que evita caer en cualquier determinismo y permite pensar en otro tipo de comunidad posible, es la condición de posibilidad de la transición hacia otra forma de ser del mundo. $\mathrm{Y}$ es lo que distingue el verdadero carácter social de la existencia humana, de las relaciones recíprocas y la cooperación mutua, naturales, que es posible observar en otras especies de animales ${ }^{10}$.

La influencia feuerbachiana se deja sentir en esta concepción de lo social y del hombre comunitario. El filósofo alemán Ludwig Feuerbach había dicho en sus Principios de la filosofía del porvenir (1843): "El ser [humano] es comunidad; el ser para sí [solipsista] es aislamiento y falta de comunitariedad", y más adelante, "únicamente es hombre el hombre social"" . Marx ratificará: "Hay que evitar, sobre todo, el volver a fijar la 'sociedad', como abstracción, frente al individuo. El individuo es el ente social” (Marx, 1968[1844]: 117). Nótese que no hay aquí ningún sentido desdeñoso del término "social" $y$, por lo tanto, ninguna contradicción entre comunidad y sociedad. A su vez, el individuo y la sociedad no son dos entidades separadas, independientes; una no surge después de la otra, sino que son al mismo tiempo, el individuo es con otros individuos y, por lo tanto, en comunidad, y la subjetividad sólo puede desarrollarse plenamente en su seno: "Solamente dentro de la comunidad [con otros tiene todo] individuo los medios necesarios para desarrollar sus dotes en todos los sentidos; solamente dentro de la comunidad es posible, por tanto, la libertad personal" (Marx y Engels, 1958[1846]: 86-87).

La epistemología marxiana se opone, pues, a cualquier solipsismo o individualismo metodológico. La contraposición individuo-sociedad no tiene sentido para Marx más que como un momento del método analítico-deductivo, y por eso denuncia ingeniosamente las robinsonadas de los economistas clásicos: "En esta sociedad de libre competencia cada individuo aparece como desprendido de sus lazos naturales, etc., que en las épocas históricas precedentes hacen de él una parte integrante de un conglomerado humano determinado y circunscrito" (Marx, 2011[1857-1858]: 3). Y da cuenta de cómo esa escisión entre el individuo y la sociedad se manifiesta a partir del momento en que las relaciones sociales dejan de considerarse el entramado constitutivo de la individualidad y se miran bajo una lógica instrumental: "Solamente al

${ }^{10}$ En una carta dirigida a su buen amigo Siegfried Meyer, el 30 de abril de 1867, Marx dice: "Si fuéramos animales, podríamos naturalmente dar la espalda a los sufrimientos de la humanidad para ocuparnos de nuestro propio pellejo" (citado en Dussel, 1988: 15). El punto relevante es esa palabra: "naturalmente". No es que los seres humanos no le den la espalda al sufrimiento de sus semejantes, pero cuando lo hacen pierden su humanidad, su esencia humana, dejan de comportarse socialmente, como seres humanos. No es nuestro interés entrar aquí en la consideración de si los animales lo hacen naturalmente o no.

11 Y en otro lugar: "La esencia del hombre está contenida únicamente en la comunidad, en la unidad del hombre con el hombre, unidad que se apoya, por lo demás, solamente en la realidad de la diferencia entre el yo y el tú", concepción de la sociedad que retomará Marx, como veremos más adelante. Todas las citas de Feuerbach provienen de Cabada (1980: 152). 
llegar el siglo XVIII, con la 'sociedad civil', las diferentes formas de conexión social aparecen ante el individuo como un simple medio para lograr sus fines privados, como una necesidad exterior" (ibídem: 4).

Por lo tanto, no hay seres humanos individuales que se unen en comunidad; la comunidad es la condición de posibilidad de la existencia de todos sus miembros y del pleno desarrollo de su subjetividad, y de las diferencias personales. La sociedad, como sistema de relaciones intersubjetivas es desde siempre (desde el inicio de la existencia humana); el "individuo" siempre nace en el seno de una comunidad, pues aun en las condiciones más desfavorables viene al mundo gracias a y con otro ser humano, su madre, y es por ello -no en virtud de su nacimiento en sí, sino por el hecho de estar con otra persona, con otros- por lo que se hace plenamente humano y social, a través del otro. No hay una sociedad formada a partir de individuos; hay seres sociales que viven en comunidad.

El carácter social de la existencia humana adquiere, entonces, un sentido inequívocamente positivo en el pensamiento de Marx; alude fundamentalmente a la conciencia de pertenencia a una comunidad, de necesidad del otro (ser humano) y de manifestación de esa totalidad (la comunidad) en la propia subjetividad. Por eso, sostiene Marx, "actúo socialmente, porque actúo como hombre. No sólo me es dado como producto social el material de mi actividad -ya que en el pensador actúa incluso el lenguaje-, sino que ya $m i$ propia existencia es actividad social; de ahí que lo que yo haga por mí lo hago por mí, para la sociedad y con la conciencia que tengo de ser un ente social" (1968[1844]: 117).

Pero -nos dice el filósofo- el carácter social de los seres humanos no está restringido a las actividades que éstos pueden compartir directamente; por el contrario, excede la práctica concreta y común, se expresa en cualquier acción o pensamiento que se dirija hacia el "ser colectivo", hacia el género humano. Alude así, implícitamente, al concepto feuerbachiano de "ser genérico": actuar como un ser genérico consciente ${ }^{12}$ significa actuar hacia los demás como hacia mí mismo y con la conciencia de ser parte de una colectividad, del género humano, es decir, tener conciencia de género, de pertenencia a la comunidad humana. En la conciencia reside la capacidad de dar forma a la comunidad de manera humana, social; de lo contrario la sociedad aparece bajo una forma

${ }^{12}$ La conciencia adquiere centralidad en la explicación de lo social o lo genérico: indudablemente somos seres sociales, pero mientras no tomemos conciencia de ello y actuemos en consecuencia, nuestra vida no responde plenamente a aquella condición. El conocimiento sobre las leyes que rigen la organización social es lo que hace posible que los seres humanos tengan un margen de acción sobre sus condiciones de vida. Mientras lo social aparezca ante nuestros ojos como algo completamente ajeno a nosotros, exterior, extraño, estaremos sometidos a nuestras propias fuerzas considerándolas independientes y sintiéndonos incapaces de modularlas. La emancipación implica, entonces, la capacidad de disponer de nosotros mismos para repensar y refundar nuestras relaciones. De lo contrario estamos bajo el influjo de la enajenación en sus más diversas formas. 
enajenada porque el ser humano mismo está enajenado, porque su forma de vivir y de trabajar no las siente como propias, sino como algo externo, impuesto desde afuera, independiente de su voluntad.

Esta comunidad son los hombres; no en una abstracción, sino como individuos particulares, vivos, reales. Y el modo de ser de ellos es el modo de ser de la comunidad. Por ello, es exactamente igual decir que el hombre se enajena de sí mismo y decir que la sociedad de este hombre enajenado es la caricatura de su comunidad real, de su verdadera vida genérica; que, por tanto, su actividad se le presenta como un tormento, su propia creación como un poder ajeno, su riqueza como pobreza; que el vínculo esencial que le une a los otros hombres se le presenta como un vínculo accesorio, y más bien la separación respecto de los otros hombres como su existencia verdadera; que su vida se le presenta como sacrificio de su vida, la realización de su esencia como desrealización de su vida, su producción como producción de su nada, su poder sobre el objeto como poder del objeto sobre él; que él, amo y señor de su creación, aparece como esclavo de esta creación (Marx, 1974[1844]: 137-138).

Es decir, la sociedad (capitalista) es la forma enajenada de la comunidad real, porque en ella todo está invertido, lo esencial aparece como accesorio, y la creación humana como imposición y opresión de los seres humanos. Por eso Marx critica el concepto de sociedad hegemónico en su época, que es el que proclamaban, entre otros, los profesores de economía. Para éstos - nos dice- la sociedad "es la sociedad civil, en la que cada individuo representa un conjunto de necesidades y sólo existe para el otro, como el otro existe solamente para él, en cuanto ambos actúan mutuamente como medios" (Marx, 1968[1844]: 144). Esta sociedad es concretamente la sociedad capitalista: un modo particular de relaciones sociales en el que los seres humanos se instrumentalizan recíprocamente, en el que han dejado de ser fines en sí mismos para convertirse en medios puestos al servicio de otros fines, a saber, la acumulación de "riqueza" y la valorización del capital, y por lo tanto los vínculos sociales aparecen como una necesidad exterior al ser humano, no como su determinación esencial. Esta sociedad es para los economistas e intelectuales liberales en general, la única existente y, dada su miopía ética o su característica argucia, también la única conveniente, por eso "tienen ante todo por objetivo demostrar la superioridad de y elogiar la sociedad, el sistema capitalista" (Marx y Engels, 1980: 34). Marx contrapone claramente aquí, la sociedad -el sistema capitalista- a las comunidades (primitivas).

Años más tarde, formulará la misma crítica de forma aún más categórica, al sostener que:

La economía política concibe a la comunidad de los hombres -es decir, a su esencia humana en acción, a su complementación en la vida genérica, en la 
verdadera vida humana- bajo la forma del intercambio y el comercio. La sociedad, dice Destutt de Tracy [...], es una serie de intercambios recíprocos. La sociedad, dice Adam Smith [...], es una sociedad de actividades comerciales. Cada uno de sus miembros es un comerciante (Marx, 1974[1844]: 138).

La "comunidad de los hombres" es, para la economía política, la sociedad capitalista. Pero esa sociedad se vive -en gran medida- como un conjunto de fuerzas externas y ajenas, avasalladoras, opresoras, cercenadoras, embrutecedoras de la humanidad. Compárese con la definición de sociedad que nos ofrece Marx en una carta dirigida a Feuerbach en la que, de manera entusiasta, le demuestra su admiración y la alta consideración en que tiene su obra: "La unidad de los hombres consigo mismos, fundada sobre la diferencia real entre los hombres; el concepto de una especie humana descendida del cielo de la abstracción a la tierra real, ¿qué puede ser esto, más que el concepto de sociedad?" (Marx, 1844).

Sostenemos entonces que no hay, en principio, oposición entre comunidad y sociedad. Ahora bien, a medida que avanzamos en un plano mayor de concreción, observamos que la sociedad que existe es la llamada sociedad capitalista, burguesa o incluso moderna, y en ella todo aparece invertido. Este tipo de sociedad es en realidad una no-sociedad, una caricatura de la sociedad o de la comunidad reales, y lo humano en ella es lo in-humano. Por ello, en la sociedad capitalista el carácter social está puesto en entredicho, cuestionado, cercenado, deformado o imposibilitado. En esto el filósofo alemán está cercano al príncipe anarco-comunista ruso cuando afirma: "En tanto que no hayamos hecho esta primera 'conquista', en tanto 'que haya pobres entre nosotros', es una burla amarga dar el nombre de 'sociedad' a este conjunto de seres humanos que se odian y se destruyen entre ellos, como animales feroces encerrados en la arena del circo" (Kropotkin, 2005[1892]: 15-16).

Veamos, entonces, cómo se configura la sociabilidad en el capitalismo.

\section{La "sociedad" capitalista}

Desde el punto de vista del desarrollo histórico, Marx observa en El Capital que: "El intercambio de mercancías comienza donde terminan las entidades comunitarias, en sus puntos de contacto con otras entidades comunitarias o con miembros de éstas. Pero - continúa- no bien las cosas devienen mercancías en la vida exterior, también se vuelven tales, por reacción, en la vida interna de la comunidad" (2011[1867]: 107). Refutando las opiniones de los más adulados economistas burgueses, el filósofo sostiene que no es posible que el intercambio de mercancías sea un elemento constitutivo originario de las comunidades porque aquél descansa fundamentalmente sobre la propiedad 
privada de los productores individuales (independientes), pues sólo el hecho de poseer con carácter exclusivo una cosa permite depositar en esa cosa la voluntad de enajenarla, es decir, desposeerse de ella y transmitir su dominio a otra persona: "La economía política, siguiendo el movimiento real, parte de la relación del hombre con el hombre como relación de propietario privado con propietario privado $[\ldots]$ resulta entonces que la pérdida de la propiedad privada o la renuncia a ella es una enajenación del hombre en tanto que propiedad privada" (Marx, 1974[1844]: 138-139).

Así pues, las relaciones de intercambio (y el dinero como equivalente general cuya única cualidad es servir como valor de cambio) surgen al o en el margen de las relaciones comunitarias y se extienden por sobre, o a costa de, ellas. En la medida en que prolifera el intercambio de mercancías (esto es, que se expande el predominio del valor de cambio) se reduce el espacio reservado a la producción de bienes destinados al propio usufructo (más que consumo), es decir, de valores de uso ${ }^{13}$. Por eso podemos afirmar que el capitalismo -en cuanto sistema peculiar de relaciones sociales- destruye las relaciones comunitarias; $\mathrm{y}$, asimismo, considerar el conjunto de relaciones sociales resultante (la "sociedad" capitalista) como opuesta a la configuración de lo social que impera en el seno de las comunidades.

Ese efecto disolvente del capitalismo -concretamente del valor de cambio y de su forma más desarrollada, el dinero- sobre las comunidades vigentes antes de su llegada y desarrollo fue claramente denunciado por Marx en los Grundrisse: "La avidez de dinero o la sed de enriquecimiento representan necesariamente el ocaso de las comunidades antiguas. De ahí la oposición a ellas. El dinero mismo es la comunidad, y no puede soportar otra superior a él. Pero esto supone el pleno desarrollo del valor de cambio y por lo tanto una organización de la sociedad correspondiente a ellos" (2011[1857-1858]: 157). Es decir, la comunidad es substituida por el dinero, que funge como el principal vínculo social -el cemento social- entre los seres humanos.

Pero indiscutiblemente en la forma capitalista de "sociedad" los seres humanos están vinculados entre sí y, en este sentido, existe un determinado tipo de relaciones "sociales". De hecho, el desarrollo de las relaciones sociales de producción y especialmente la profundización de la división social del trabajo producen un entramado de relaciones inter-individuales que hacen que cada persona dependa, crecientemente, para su subsistencia de las demás. El aumento de la inter-dependencia es una de las características positivas que destacó Marx de la "sociedad" capitalista. Sin embargo estas relaciones y su naturaleza presentan un carácter inconsciente e indirecto para los individuos involucrados

${ }^{13}$ Marx define el valor de uso como una cosa útil producida por el trabajo humano; el valor de cambio es la expresión del valor -trabajo objetivado- contenido en el valor de uso; al respecto véase el capítulo 1 del tomo 1 del libro I de El Capital.

Araucaria. Revista Iberoamericana de Filosofía, Política y Humanidades, año 17, n⿳ 34. Segundo semestre de 2015. Pp. 109-132. ISSN 1575-6823 e-ISSN 2340-2199 doi: 10.12795/araucaria.2015.i34.06 
en ellas. La condición social de este modo de producción predominante y de este tipo de sociedad, aparece sólo a posteriori, en la esfera de la circulación de mercancías, en el mercado, por medio del intercambio, de la compra y de la venta. Sólo ahí, en ese "tráfico sórdido" (Marx, 1974[1844]: 113) del mercado se pone de manifiesto el carácter "social" de la producción bajo este nuevo mundo, a través del dinero, que es ese producto social de todos, y por eso, en la sociedad burguesa, nos dice Marx, "su poder social, así como su nexo con la sociedad, lo lleva consigo en el bolsillo" (2011[1857-1858]: 84). El carácter social de la producción y de la participación en la producción se presenta para los productores como algo ajeno y en forma de cosa, "no como su estar recíprocamente relacionados, sino como su estar subordinados a relaciones que subsisten independientemente de ellos y nacen del choque de los individuos recíprocamente indiferentes" (ídem).

Como señala con claridad meridiana el filósofo y economista alemán Franz Hinkelammert (1989): "El mercado une los contrarios, los opuestos, que mediante el mercado llegan a ser una identidad. Así aparece la gran utopía burguesa, producida por una mano invisible y providencial que actúa en el mercado. Con esta utopía burguesa aparece el nuevo mito de la sociedad". El carácter mítico, inventado, no real, de la sociedad capitalista reside, pues, en el hecho de que la unidad entre los individuos no descansa en su relación directa, en el intercambio de bienes y la satisfacción de necesidades recíprocas, sino en la interacción diferida y mediada a través del dinero en el mercado. Los seres humanos no se relacionan entre sí, primordialmente, como personas o individuos y por las cualidades que les son propias, sino en cuanto vendedores y compradores de cosas ajenas.

Así pues, la "sociedad" capitalista (con el predominio del valor de cambio y del dinero, que es su expresión más desarrollada) se funda y produce un tipo de relaciones en el que los individuos, mutuamente indiferentes entre sí, están recíprocamente ligados a través de sus productos (mercancías). Y esto porque "los hombres depositan en la cosa [[material]] (en el dinero) aquella confianza que no están dispuestos a depositar en ellos mismos como personas" (Marx, 2011[1857-1858]: 88). Pero para que ello sea posible, se requiere al mismo tiempo la independencia (o indiferencia) absoluta de los productores y una ampliamente desarrollada división del trabajo social, cuya articulación aparece como "una relación natural externa a los individuos, independiente de ellos" (ibídem: 85-86). Los individuos son indiferentes y sólo a través del mecanismo impersonal, social, de la oferta y la demanda, arriban a la unidad y la complementariedad. Lo "social", entonces, funciona como una coacción interna ${ }^{14}$ que obliga al individuo, aunque aparentemente éste actúa voluntaria y libremente en dicho sistema de relaciones. Por eso dice Marx: "Los individuos

${ }^{14}$ O de otra forma: "El capital se convierte [...] en una relación coactiva" (Marx, 2011[1867]: 376). 
están subordinados a la producción social, que pesa sobre ellos como una fatalidad; pero la producción social no está subordinada a los individuos y controlada por ellos como un patrimonio común” (ibídem: 86).

Podemos concluir pues, con Marx, que la sociedad que debería ser entendida como la comunidad humana (y en este sentido, ambos términos son equivalentes) está transfigurada en un engendro comercial; la comunidad aparece bajo la forma de la sociedad comercial. La inversión y la ocultación características de la conciencia necesariamente mixtificada que emerge bajo el capitalismo, sólo pueden presentar la sociedad bajo su forma enajenada. Así, la sociedad como "sociedad" burguesa es vista como la única posible, la única verdaderamente humana, la única adecuada a la "naturaleza" humana. Y sin embargo, el filósofo reconoce que este modo de producción ha revolucionado de tal forma las condiciones y las relaciones de producción que ha permitido desarrollar enormemente las capacidades para una vida verdaderamente social; existencia que no será posible sino después del fin del capitalismo, pero que éste, a su parecer, posibilita. Esta última proposición será la que discutiremos a continuación.

\section{La otra comunidad posible: La sociedad comunista o la comunidad social}

Marx dedicó pocos escritos a aventurar cómo sería la futura sociedad comunista, algo que entraba, a su parecer, dentro del ámbito de la ciencia ficción, y no de la ciencia social. No obstante, su penetrante análisis de la sociedad burguesa y de las contradicciones inherentes al modo de producción capitalista, le hicieron un ferviente convencido de la inevitabilidad de la transición hacia una sociedad más humana. Por eso, con un optimismo a toda prueba declaraba: "La prostitución general se presenta como una fase necesaria del carácter social de las disposiciones, capacidades, habilidades y actividades personales" (Marx, 2011[1857-1858]: 90). Por otra parte, dedicó algunos pasajes a analizar las formaciones sociales previas a la moderna sociedad burguesa en los que es posible reconstruir su valoración, plagada de claroscuros, sobre las mismas: una mirada extremadamente lúcida y crítica, y una henchida fe en el progreso arrojan una interpretación predominantemente negativa sobre las formas comunitarias pretéritas. Finalmente, nuestro filósofo revolucionario criticó áspera y profusamente los intentos de establecer comunidades, es decir, comunas $\mathrm{u}$ organizaciones sociales regidas por principios contrapuestos a los que fundan la sociedad burguesa; ensayos en los que se esforzaron los -bautizados por él mismo- "socialistas utópicos", que calificó como experimentos absurdos, elitistas, a-científicos y destinados indefectiblemente al más rotundo fracaso por estar basados únicamente en buenas intenciones y por carecer de cualquier 
asidero en la realidad y en las leyes que rigen la sociedad.

Fue, sin embargo, la reflexión iniciada a propósito de las características de la obschina rusa y de las posibilidades de emplearla como base desde la cual iniciar la construcción de la sociedad comunista - posibilidad defendida por los narodniki (populistas) rusos- la que arroja una idea más diáfana sobre el pensamiento marxiano al respecto. En esos escritos encontramos una caracterización clara sobre las comunidades pretéritas: "Este tipo primitivo de la producción colectiva o cooperativa fue, claro está, consecuencia de la debilidad del individuo aislado [sic.] y no de la socialización de los medios de producción" (Marx y Engels, 1980: 35). Marx hace hincapié en la situación de debilidad de las colectividades originarias para satisfacer enteramente sus necesidades -en la escasez-, dadas unas condiciones naturales desfavorables y un limitado desarrollo de las potencialidades sociales -en el sentido de la fuerza resultante de la cooperación y la complementariedad-, lo que hace que la apropiación común, la interdependencia material, sea una necesidad natural, una condición para su supervivencia, pero no resultado, todavía, de la decisión libre de los seres humanos de poner bajo control común los medios de producción que garanticen la existencia de la comunidad. Por eso, para que la comunidad social futura sea posible "la dependencia recíproca debe haber alcanzado todo su relieve antes de que se pueda pensar en una verdadera comunidad social. Todas las relaciones como puestas por la sociedad; no como determinadas por la naturaleza" (Marx, 2011[1857-1858]: 218).

En estas comunidades primitivas lo social estaría escasamente desarrollado, y en todo caso, sería impuesto como necesidad ciega, es decir, sin que el ser humano tenga conciencia de ello (por lo tanto negando la libertad del ser humano $)^{15}$. En consecuencia, la futura comunidad social consistiría en "el retorno de las sociedades modernas a una forma superior de un tipo 'arcaico' de la propiedad y la producción colectivas" (Marx y Engels, 1980: 38-39). Es decir, hay una consideración de las formas comunitarias previas y de su modo de producción basado en la propiedad común como el deber ser de la sociedad comunista imaginada; es ese elemento - la propiedad común y el usufructo, por lo tanto, también común, de los bienes naturales y sociales- lo que rescata Marx de la forma de sociabilidad de las comunidades pretéritas. Por eso agrega en su característico tono irónico: "Luego no hay que asustarse demasiado de la palabra "arcaico"” (ibídem: 33). Sin embargo no se tratará de las mismas formas pasadas, sino de una forma superior de aquel tipo arcaico. ¿Y por qué

\footnotetext{
${ }^{15}$ Para Hegel la libertad es la conciencia de la necesidad. Y, en esto, Marx también es profundamente hegeliano. Engels afirma en el Anti-Dühring que "Hegel ha sido el primero en exponer rectamente la relación entre libertad y necesidad. Para él, la libertad es la comprensión de la necesidad. [...] La libertad no consiste en una soñada independencia respecto de las leyes naturales, sino en el reconocimiento de esas leyes y en la posibilidad, así dada, de hacerlas obrar según un plan para determinados fines" (1986 [1878]: 105).
} 
superior? En primer lugar, porque en ella el carácter social será plenamente puesto por los hombres y las mujeres, conscientes de su capacidad de controlar y modelar su sociabilidad y de dar forma a la sociedad. En segundo lugar, porque las posibilidades materiales para la satisfacción de las necesidades de los seres humanos será "completa" (a diferencia de lo que sucede, a su juicio, en el comunismo primitivo), garantizando así la abundancia: "Los individuos universalmente desarrollados, cuyas relaciones sociales en cuanto relaciones propias y colectivas están ya sometidas a su propio control colectivo, no son un producto de la naturaleza, sino de la historia" (Marx, 2011[1857-1858]: 89-90).

De esta manera, el verdadero comunismo, no el "comunismo tosco"16, consiste precisamente en "el retorno total, consciente y logrado dentro de toda la riqueza del desarrollo anterior, del hombre para sí como un hombre social, es decir, humano" (Marx, 1968[1844]: 114).

Hay en Marx una mirada en exceso prejuiciada y errónea sobre las condiciones y la idiosincrasia de las comunidades pretéritas. Esta visión será en parte corregida en los escritos referidos a la comuna rural rusa, en los últimos años de su vida, aunque hará hincapié, entonces, en el peligro de autoritarismo que amenaza esas comunidades; pues presenta a la comunidad con potencialidades para desarrollar otro modo de sociabilidad en el que no impere el valor de cambio, pero también con tendencias a clausurar el desarrollo de la individualidad, las diferencias personales, los talentos, etc. Claro está que para Marx la posibilidad de que a partir de la obschina se pudiera transitar hacia formas colectivistas de producción y distribución se sustentaba en la generalidad que poseía todavía ese modo de vivir y de producir en la Rusia de finales del siglo XIX, es decir, en el carácter extenso y general de su implantación en el territorio nacional. Si la obschina hubiera estado reducida a unos pocos lugares y hubiera constituido ya más bien una reliquia del pasado y no una forma social con presencia en todo el territorio ruso, es dable pensar que no la habría considerado de igual modo.

La otra condición que otorga a la comunidad rural rusa posibilidades de desarrollarse en una orientación socialista, sin atravesar por el capitalismo, es precisamente la existencia misma de éste último en Europa Occidental y la opción, por tanto, de beneficiarse de sus "logros" sin padecer sus vicisitudes. Porque este modo de producción, con todos los males que trae aparejados, constituye - a juicio de Marx- un elemento que ha revolucionado y desarrollado las fuerzas productivas, y ello podría garantizar la suficiencia de medios de producción y de bienes para satisfacer las necesidades de toda la población. De acuerdo con esta lectura, es el carácter revolucionario del capitalismo -e incluso

\footnotetext{
${ }^{16}$ Expresión que Marx empleara para referirse a algunos socialistas y comunistas de su época que proponían una generalización de la propiedad privada, pero no entendían que el comunismo debía ser la supresión absoluta de toda forma de propiedad: por lo tanto la comunidad, en donde desaparece cualquier expresión del tener. Ver Marx, 1968 (1844).
} 
más, la "esencia positiva de la propiedad privada" (Marx, 1968[1844]: 114)lo que ha asegurado las condiciones para pasar del "reino de la necesidad" al "reino de la libertad".

Esta confianza en el carácter históricamente necesario del capitalismo será precisamente la tesis que Marx revisará en los apuntes para responder a Zasúlich, al referirse a la cuestión agraria en Rusia. Para algunos, la carta de Marx supone algo así como una "herejía" teórica con respecto a la interpretación ortodoxa de su obra, en el sentido de la "fatalidad histórica" de la disolución de la comunidad rural, que supuestamente se derivaba de la teoría histórica contenida en El Capital (Kohan, 1998: 244-245). El propio autor se encargará de cuestionar esa extrapolación de su análisis, que explícitamente se circunscribía a los países de Europa Occidental, "porque en Rusia, gracias a una excepcional combinación de circunstancias, la comuna rural, establecida todavía a escala nacional, puede irse desprendiendo de sus caracteres primitivos y desarrollando directamente como elemento de la producción colectiva a escala nacional" (Marx y Engels, 1980: 32). Ahora bien, la comuna rural rusa vivía acechada por múltiples trabas -impuestos y cargas- que limitaban sus potencialidades, por eso el filósofo alemán considera que "para salvar a la comuna rusa hace falta una revolución rusa", y agrega, que "si la revolución se efectúa en el momento oportuno, si concentra todas sus fuerzas [...] en asegurar el libre desenvolvimiento de la comuna rural, ésta se revelará pronto como un elemento regenerador de la sociedad rusa y un elemento de superioridad sobre los países subyugados por el régimen capitalista" (ibídem: 45). Marx no advierte, pues, imposibilidad teórica en una evolución de tal tipo, aunque sí dificultades históricas.

Con todo, es innegable el carácter "progresista" de la concepción de la historia que subyace en el análisis marxiano. Si bien es cierto que en los escritos citados más arriba el autor plantea la posibilidad de que Rusia soslaye el capitalismo, éste sigue apareciendo recubierto de una "bondad" histórica, proporcionada por su "utilidad" como elemento revolucionario de las fuerzas productivas. Esta concepción edulcorada del capitalismo -en cuanto paso necesario en el proceso de liberación humana- ha sido rebatida, por ejemplo, por Silvia Federici, en su revisión, desde una perspectiva feminista, del análisis de la llamada acumulación originaria de Marx. Para la historiadora italiana, el análisis marxiano del proceso de acumulación del capital sugiere "necesidad, inevitabilidad y, finalmente, progreso" (Federici, 2010[2004]: 92). Y agrega:

Marx enfatizó también la productividad del trabajo al que los trabajadores están subordinados -una productividad que para él es la condición para el futuro dominio de la sociedad por los trabajadores. Marx no observó que el desarrollo de las potencias industriales de los trabajadores fue a costa del subdesarrollo de sus poderes como individuos sociales, aunque reconociese que los trabajadores en la sociedad capitalista están tan alienados de su trabajo, de sus relaciones 
con otros y de los productos de su trabajo como para estar dominados por éstos como si se tratara de una fuerza ajena" (ibídem: 28).

Por el contrario, el análisis de Federici, partiendo de las transformaciones que el capitalismo introdujo en la reproducción de la fuerza de trabajo y en la posición social de las mujeres, concluye que de ningún modo este sistema significó un "avance" o una "liberación" para los hombres y las mujeres, en conjunto. Por eso sostiene que "Marx nunca podría haber supuesto que el capitalismo allanaba el camino hacia la liberación humana si hubiera mirado su historia desde el punto de vista de las mujeres" (Federici, 2010[2004]: 24). Así considerada, la llamada acumulación primitiva destruyó el poder de las comunidades rurales, y el lugar significativo que las mujeres ocupaban en ellas, debilitó las relaciones sociales basadas en la colaboración, desproveyó a los sectores populares de los medios de subsistencia garantizados por el usufructo de los commons $^{17}$ e introdujo profundas divisiones en el interior del proletariado -como las de género, "raza" y edad-que han servido para "intensificar y ocultar la explotación” (ibidem: 90).

Además de contradecir a Marx en este punto, Federici sostiene que contrariamente a la imagen corriente de la Edad Media como una época oscura, estática, caracterizada por la ignorancia y dominada por una bruma espesa que mantenía a cada uno en su lugar, su reconstrucción de ese período arroja un cuadro muy distinto: el de unas sociedades envueltas en una "lucha de clases implacable" (Federici, 2010[2004]: 42). La aldea feudal resistió enérgicamente su destrucción y se opuso encarecidamente a la imposición de las nuevas regulaciones introducidas por el capitalismo, "lo que indica que el mundo precapitalista de la aldea, que Marx desvalorizó llamándola «idiotez rural»» ${ }^{18}$, pudo producir un nivel de luchas tan elevado como cualquiera que haya librado el proletariado industrial" (ibídem: 124). De hecho, de acuerdo con la autora,

\footnotetext{
17 Término que se ha traducido como "tierras comunales" o "lo común", según el caso.

${ }^{18} \mathrm{La}$ autora se refiere a la siguiente expresión del Manifiesto del Partido Comunista que constata la visión progresista que compartían Marx y Engels: "La burguesía ha sometido el campo al dominio de la ciudad. Ha creado urbes inmensas; ha aumentado enormemente la población de las ciudades en comparación con la del campo, substrayendo una gran parte de la población al idiotismo de la vida rural. Del mismo modo que ha subordinado el campo a la ciudad, ha subordinado los países bárbaros o semibárbaros a los países civilizados, los pueblos campesinos a los pueblos burgueses, el Oriente al Occidente" (Marx y Engels, 2005[1848]: 107). Cabe señalar sin embargo, que la consideración marxiana del mundo campesino no era tan unilateral y despectiva como, a simple vista haría suponer esta afirmación. En otro trabajo sostiene: "La contraposición entre la ciudad y el campo sólo puede darse dentro de la propiedad privada. Es la expresión más palmaria de la absorción del individuo por la división del trabajo, por una determinada actividad que le es impuesta, absorción que convierte a unos en limitados animales urbanos y a otros en limitados animales rústicos, reproduciendo diariamente este antagonismo de intereses. El trabajo vuelve a ser aquí lo fundamental, el poder sobre los individuos, y mientras exista este poder, tiene que existir necesariamente la propiedad privada. La abolición de la antítesis entre la ciudad y el campo es una de las primeras condiciones para la comunidad" (Marx y Engels, 1958[1846]: 56).
} 
"el capitalismo fue la contrarrevolución que destruyó las posibilidades que habían emergido de la lucha anti-feudal" (ibídem: 34). En esas luchas, las mujeres tuvieron un papel protagónico, que se corresponde con la virulencia del ataque desatado contra ellas por medio de la caza de brujas, aspecto que pasó desapercibido en la obra de Marx.

Ciertamente, la confianza que expresó Marx en la necesidad histórica del capitalismo y sus "consecuencias" positivas para la liberación humana, una vez que las fuerzas sociales que había desatado fueran reapropiadas y reconducidas conscientemente por los hombres y las mujeres, plantea algunas dudas a la luz del desarrollo histórico posterior. Precisamente Federici se encarga de evidenciar el carácter recurrente de los procesos de "acumulación primitiva" -división de comunidades, privatización y expropiación de tierras y de otros recursos naturales y saqueo- siempre que el capitalismo requiere dar un nuevo impulso a su afán acumulativo; y la actualización de la caza de brujas como una estrategia para criminalizar la resistencia de las comunidades, y particularmente de las mujeres, a esa expropiación y al cercamiento de tierras, de cuerpos, de saberes. De ahí la importancia que ha adquirido el concepto de "commons" en las luchas anticapitalistas actuales.

Con todo, Marx no fue ciego al carácter depredador y alienante del modo de producción capitalista, aunque sí fue bastante indiferente a la suerte particular que las mujeres corrían bajo su dominio. Si bien algunos pasajes de su obra traslucen una valoración eminentemente despectiva de la vida bajo otras formas sociales de producción, manifestando una suerte de linealidad en su concepción de la historia, como cuando afirma: "La contradicción entre el campo y la ciudad comienza con el tránsito de la barbarie a la civilización, del régimen tribual al Estado, de la localidad a la nación, y se mantiene a lo largo de toda la historia de la civilización hasta llegar a nuestros días" (Marx y Engels, 1958[1846]: 55), no es menos cierto que en otras ocasiones dejó expresa constancia del carácter ambivalente de las posibilidades históricas. Así, con respecto a la comuna rural rusa afirmó: "Su dualismo innato admite una alternativa: su elemento de propiedad triunfará del elemento colectivo, o bien éste triunfará de aquél. Todo depende del medio histórico donde se encuentre colocada" (ídem). De esta forma daba cuenta del carácter contradictorio, ambivalente, de la "forma comunidad", presentándola como un conjunto de potencias, cuya posibilidad histórica se definiría en función de las luchas concretas.

De este recorrido por los escritos de Marx a propósito de la obschina, rescatamos la relevancia de la apropiación común y el predominio de la producción de valores de uso, como elementos fundantes de otro tipo de sociedades. Esos dos elementos prevalecen en las comunidades y nos parecen sus dos determinaciones principales. Sin embargo, consideramos con Marx, 
que lo común va más allá de la propiedad; no se trata solamente de la oposición a la propiedad privada sino de pensar la comunidad más allá de la propiedad (sin desconocer la importancia del elemento económico-productivo): "La superación positiva de la propiedad privada $[\ldots]$ no debe concebirse solamente en el sentido del goce directo, unilateral, en el sentido de la tenencia o posesión. [...] La propiedad privada nos ha vuelto tan estúpidos y unilaterales, que sólo consideramos que un objeto es nuestro cuando lo tenemos [...] en una palabra, cuando lo usamos" (Marx, 1968[1844]: 118).

Por otra parte, el carácter social de la vida en común de los hombres y las mujeres implica, para Marx, una completa interdependencia entre ellos y la conciencia de dirigir, en común, los designios de esa vida, por contraposición a la vida signada por las necesidades materiales y las coerciones naturales que forzaron también la agrupación y la colaboración de las personas en épocas pasadas, pero no como resultado de su propia elección sino como consecuencia del "estado de necesidad". No olvidemos que en el esquema desiderativo de Marx el socialismo se ubicaba como el "estadio" siguiente al capitalismo y el comunismo era entendido no como un modo de producción ni como una formación económico-social sino como la lucha por romper con la sociedad capitalista y arribar a una "verdadera comunidad social". Marx y Engels sostienen, en La ideología alemana: "Para nosotros, el comunismo no es un estado que debe implantarse, un ideal al que haya de sujetarse la realidad" (Marx y Engels, 1958[1846]: 37). Ya hemos señalado que el comunismo es, pues, un movimiento, el movimiento que se opone al "estado de cosas actual" y que busca, por ende, re-humanizar, re-socializar, re-comunizar las relaciones entre los seres humanos y de éstos con las otras especies animales y vegetales.

\section{Consideraciones finales}

El "vaciamiento completo" al que aludía Marx en los Grundrisse avanzó durante el siglo XX disolviendo todas las relaciones y los espacios en los que latía una alta densidad humana. "Don dinero" extendió su potestad niveladora de todas las diferencias individuales, igualando a las personas en su "derecho" a ser convertidas en medios de valorización del valor. Frente a ello, algunas comunidades resistieron los embates del capitalismo y perseveraron en sus usos y costumbres, en abierta contradicción o en disimulada discordancia, según el caso y el momento, con la lógica mercantilista. Desde la pervivencia de esas comunidades fue posible desplegar un redivivo antagonismo contra el sistema capitalista, cuya "voracidad canibalesca de plustrabajo" (Marx, 2011[1867]: 292) lo fuerza a avasallar todo a su paso. Es ese protagonismo -cuya forma más diáfana en América Latina son las comunidades indígenas, rurales, pero 
que resurge también en colectivos y comunidades urbanas por todo el mundoel que ha permitido repensar la comunidad y valorizarla no como una forma pretérita o ilusoria, sino como expresiones concretas y actuales de un tipo de relaciones sociales que superponen el bienestar de las personas, en cuanto seres sociales, comunitarios, a la explotación de unos sobre otros.

Sin embargo, la revitalización de las nociones de comunidad y de "lo comunitario" actualiza la dicotomía entre la sociedad y la comunidad y, con ella, el riesgo de volver a fijar estos conceptos como entidades o configuraciones contrapuestas. De hecho algunos estudios avanzan en ese sentido, esta vez relevando a la comunidad por sobre la sociedad. Es el caso del análisis del filósofo boliviano Juan José Bautista, para quien los movimientos de los pueblos originarios "no son sociales porque no tienen conciencia 'social', sino que son movimientos comunitarios, pero no sólo porque tienen conciencia 'comunitaria', sino porque no aspiran a reproducir entre ellos la forma de vida 'social' que ha producido la modernidad y el capitalismo" (Bautista, 2012: 188). Y esto porque "la modernidad para poder afirmar a la 'sociedad moderna' como la forma de vida ideal de la humanidad, antes tiene que prejuiciar como caduca, obsoleta e inferior racial y culturalmente, a toda forma de vida anterior a ella" (ibídem: 189). En el prólogo a esta obra, el filósofo uruguayo Yamandú Acosta sostiene que los "movimientos comunitarios como pueden serlo los movimientos de los pueblos originarios en Bolivia, Ecuador y Perú, como lo son de colectivos que no tienen una conciencia social moderna sino una conciencia comunitaria trans-moderna, no pueden ser aproximados a los efectos de su inteligibilidad con la categoría de "movimiento social"' (Acosta, 2012: 33). Por esa vía se señala que los movimientos sociales "nacen" con el capitalismo y, aunque se orientan a trascender el capitalismo, no logran superar la lógica moderna por lo que indirectamente refuerzan al primero, pues de acuerdo con esta lectura, capitalismo y modernidad van de la mano. De esta manera:

En la reducción de los movimientos comunitarios trans-modernos a la de movimientos sociales modernos, se estaría incurriendo 'ingenuamente en la racialización de la ciencia social moderna' implicando en la misma que los movimientos comunitarios tendrían que modernizarse, esto es, adquirir conciencia social moderna, para constituirse en efectivos movimientos sociales con efectiva capacidad crítico-transformadora, constitutiva y constituyente de la modernidad y no de la premodernidad (Acosta, 2012: 33-34).

Concordamos con ambos filósofos en que los movimientos comunitarios no se proponen reproducir el tipo de relaciones sociales que imperan en la sociedad burguesa y también en que la modernidad capitalista requirió una operación de denigración de las comunidades para proponerse ante los ojos del mundo como 
un modo superior de vida. Sin embargo, nos parece equivocado recurrir, ahora, a la desvalorización de los movimientos sociales y al cuestionamiento de sus capacidades transformadoras, para realzar a la comunidad. En todo caso, no nos interesa tanto salvaguardar el propio concepto como llamar la atención sobre los peligros de menospreciar ciertas luchas. Si bien es cierto que la categoría de "movimiento social" es un producto moderno, hija de la sociología, no lo es menos que las luchas de distintos grupos sociales por oponerse a la deshumanización provocada por el imperio del capital arraiga en prácticas y vivencias de tipo comunitario, que reproducen sentidos de pertenencia a una comunidad. De otra parte, no podemos desconocer que las comunidades indígenas y campesinas, aun cuando han logrado preservar sus formas de vida, han entrado en contacto en mayor o menor medida con las dinámicas del capital y, por lo tanto, se han visto atravesadas por las contradicciones que éste comporta. Enfrentar ahora los movimientos comunitarios a los movimientos sociales lejos de contribuir a pensar la trasformación a partir de la multiplicación de rebeldías, contribuye a dividir una vez más a quienes tratan de re-humanizar la sociedad.

Otros análisis, por el contrario, retornan a la consideración de la comunidad de manera restringida, como un espacio definido por características heredadas, por la adscripción de sus miembros al nacer y, por lo tanto, por el carácter cerrado, estático, contrario al cambio y a la innovación. Por ende, se refuerza la tendencia a enfatizar los elementos culturales para establecer distinciones que dificultan la comunicación entre distintas comunidades. De esta manera, se sostiene que "mientras los movimientos sociales reflejan la división de una sociedad, los movimientos comunitarios apelan a la unidad del cuerpo social o de cualquier otra colectividad. Al apelar a la unidad o incluso a la homogeneidad de la colectividad, la identidad comunitaria genera una preocupación por la pureza y por expulsar de ella a los elementos considerados impuros" (Solana, 2000: 118). Por esa vía, los movimientos comunitarios se acercan al racismo y a la intolerancia. Esta interpretación es claramente deudora del debate sociológico clásico y reproduce la noción de la comunidad en su consideración negativa, conservadora, fundamentalista. Así, se establece que "la noción de movimiento comunitario se aproxima, en muchos aspectos, y sobre todo con las formas comunitarias vinculadas a la formación y el ocaso de movimientos sociales, a la de antimovimiento social" (ídem). De esta forma $\mathrm{y}$, en el sentido opuesto, también los movimientos comunitarios se contraponen a los movimientos sociales.

Ambas derivas teóricas reproducen, a nuestro juicio, la infértil contraposición categorial que contrapone la comunidad a la sociedad -y viceversa-, pensándolas en definitiva como entidades cerradas, homogéneas, delimitadas ex ante, definidas de una vez para siempre. La revisión de las proposiciones y reflexiones de Marx a propósito de la comunidad permite, a 
nuestro juicio, superar esa dicotomía y arroja algunas perspectivas sugerentes. Nos parece de particular relevancia, en primer lugar, la necesidad de considerar a la comunidad no como un ente definido ad eternum, inmutable, presencia estática del pasado en el presente, sino como una forma de sociabilidad que tiende a la apropiación consciente por parte de sus integrantes de sus medios de existencia, a la deliberación y al consenso de los propósitos colectivos, a la consideración de las personas como fines en sí mismos y no como instrumentos para los fines de otros, y a la relación armónica con la naturaleza, en la medida en que el ser humano es también un ser natural. En segundo lugar, y tomando en cuenta lo anterior, la comunidad está atravesada por antagonismos y contradicciones, por lo que sería conveniente huir de la tentación de considerarla sólo en sus aspectos positivos, como expresión de una "plenitud primitiva". Las precauciones de Marx al respecto y su propia concepción dialéctica de los procesos históricos deberían contribuir a pensarla como un proceso en el que se despliegan sus potencialidades de afirmación de la dignidad humana, pero también las propias tendencias que la niegan. Es desde esta dinámica de las contradicciones desde donde es posible captar lo novedoso en las formas comunitarias y poner en valor, entonces, su capacidad para avanzar hacia una sociedad más humana, más común, más social. Por último y, a modo de conclusión, pensamos que la comunidad no es algo dado, independiente de la voluntad, un "lugar" en el que se nace, la familia a la que se pertenece o el barrio en el que se vive; la comunidad puede ser un deseo y, como tal, una construcción colectiva, deliberada, incesante, de un mundo mejor. 


\section{Referencias bibliográficas:}

Acosta, Y. (2012). Prólogo. En Bautista, J. J., Hacia la Descolonización de la Ciencia Social Latinoamericana. Cuatro ensayos metodológicos y epistemológicos. La Paz: Rincón Ediciones, 11-39.

Agamben, G. (1996[1990]). La comunidad que viene. Valencia, PreTextos.

Bautista, J. J. (2012). Hacia la Descolonización de la Ciencia Social Latinoamericana. Cuatro ensayos metodológicos y epistemológicos. La Paz: Rincón Ediciones.

Cabada, M. (1980). Feuerbach y Kant: dos actitudes antropológicas. Madrid: Publicaciones de la Universidad Pontificia Comillas.

De Marinis, P. (2010a). Comunidad: derivas de un concepto a través de la historia de la teoría sociológica. Papeles del CEIC (58), http://www. identidadcolectiva.es/pdf/intro.pdf.

De Marinis, P. (2010b). La comunidad según Max Weber: desde el tipo ideal de la Vergemeinschaftung hasta la comunidad de los combatientes. Papeles del CEIC (58), http://www.identidadcolectiva.es/pdf/58.pdf.

Durkheim, É. (2001[1893]). La división del trabajo social. Madrid: Akal.

Dussel, E. (1988). Hacia un Marx desconocido. Un comentario de los Manuscritos del 61-63. México: Siglo XXI.

Engels, F. (1986 [1878]). La revolución de la ciencia de Eugenio Dühring (“Anti-Dühring”). En Marx, K. y Engels, F. Obras fundamentales. Vol. 18. Engels. Obras filosóficas. México: FCE.

Engels, F. (s/f [1884]). El origen de la familia, la propiedad privada y el Estado. Moscú: Ediciones en Lenguas Extranjeras.

Esposito, R. (2003[1998]). Communitas: origen y destino de la comunidad. Buenos Aires: Amorrortu.

Farfán, R. (1998). F. Tönnies: La crítica a la modernidad a partir de la comunidad. En Zabludovsky, G. (coord.). Teoría sociológica y modernidad. Balance del pensamiento clásico. México: FCPyS-UNAM/Plaza y Valdés, 187-212.

Federici, S. (2010[2004]). Calibán y la bruja. Mujeres, cuerpo y acumulación originaria. Madrid: Traficantes de Sueños.

García, Á. (2009). Forma valor y forma comunidad. Aproximación teóricaabstracta a los fundamentos civilizatorios que preceden al Ayllu Universal. La Paz: Clacso/Muela del Diablo/Comuna.

Hinkelammert, F. (1989). Economía y teología: las leyes del mercado y la fe. Disponible en: http://www.pensamientocritico.info/articulos/articulos-defranz-hinkelammert/102-economia-y-teologia-las-leyes-del-mercado-y-la-fe. html,1989 
Kohan, N. (1998). Marx en su (Tercer) Mundo. Hacia un socialismo no colonizado. Buenos Aires: Biblos.

Kropotkin, P. (2005[1892]). La conquista del pan. Buenos Aires: Libros de Anarres.

Marx, K. (1844). Carta a Ludwig Feuerbach (11 de agosto). En Marx, K. y Engels, F. Obras fundamentales. Tomo 1. Marx. Escritos de Juventud. México: FCE, 679-681.

Marx, K. (1845). Tesis sobre Feuerbach. Disponible en www.marxists.org.

Marx, K. (1968[1844]). Manuscritos económico-filosóficos de 1844. En Marx, K. y Engels, F. Escritos económicos varios. México: Grijalbo, 25-125.

Marx, K. (1971[1852]). El dieciocho brumario de Luis Bonaparte. En Marx, K. y Engels, F. Obras escogidas en dos tomos (Vol. 1). Moscú: Progreso, 226-323.

Marx, K. (1974[1844]). Cuadernos de París [Notas de lectura de 1844] (Estudio previo de Adolfo Sánchez Vázquez). México: ERA.

Marx, K. (2011[1857-1858]). Elementos fundamentales para la crítica de la economía política (Grundrisse) 1857-1858, Vol. 1. México: Siglo XXI.

Marx, K. (2011[1867]). El Capital (Vol. 1/Tomo I). México: Siglo XXI.

Marx, K. (2013[1867]). El Capital (Vol. 3/Tomo I). México: Siglo XXI.

Marx, K. y Engels, F. (1958[1846]). La ideología alemana. Montevideo: Ediciones Pueblos Unidos.

Marx, K. y Engels, F. (1980). Escritos sobre Rusia, II. El porvenir de la comuna rural rusa. México: Ediciones Pasado y Presente.

Marx, K. y Engels, F. (2005[1848]). Manifiesto del Partido Comunista. Buenos Aires: Longseller.

Nancy, J.-L. (2000[1983]). La comunidad inoperante. Santiago: LOM/ Arcis.

Prada, R. (2008). Subversiones indigenas. La Paz: Clacso/Muela del Diablo/Comuna.

Solana, J. L. (2000). Identidad cultural, racismo y antirracismo. En Gómez, P. (Coord.). Las ilusiones de la identidad. Madrid: Frónesis. Cátedra Universitat de València, 99-126. 